\title{
On-line focus group: uma possibilidade para a pesquisa qualitativa em administração
}

\author{
Online focus group: a possibility for the qualitative research in administration
}

\author{
Christine da Silva Schröeder ${ }^{1}$ \\ Luis Roque Klering ${ }^{2}$
}

\section{Resumo}

A utilização de grupos focais (focus groups) como técnica de pesquisa representa uma alternativa interessante para o desenvo/vimento de estudos qualitativos. Normalmente, os focus groups envolvem de seis a 10 pessoas que se reúnem para discutir tópicos específicos acerca de alguma temática, observando-se que a interação entre os membros do grupo também é tida como dado da pesquisa. Além disso, ao se considerar a influência das tecnologias de informação, em especial da Internet, a técnica pode ser aplicada virtualmente - através de on-line focus groups (OFGs) -, com auxilio de ferramentas como e-mail, chats e listas de discussão. Uma vez que, através de uma análise da produção acadêmica nacional em administração, constata-se que o emprego da técnica de focus group parece ser ainda incipiente - em especial, na modalidade on-line -, este artigo objetiva, a partir da revisão da literatura afim, caracterizar os OFGs e descrever sua forma de condução, bem como elencar as possíveis vantagens e desvantagens decorrentes de seu emprego, sugerindo sua utilização em pesquisas qualitativas em administração.

Palavras-chave: grupos focais; pesquisa qualitativa; tecnologia de informação

\section{Abstract}

The use of focal groups (focus groups) as a technique of research represents an interesting alternative to the development of qualitative studies. Normally, this technique involves the participation of 6 to 10 respondents which discuss specific topics about some subject, and the interaction that occurs between the members of the group is also considered an important data. Also, while it considers the influence of the technologies of information, specially the internet, the technique can still be applied virtually - through on-line focus groups (OFGs) -, through the use of tools like e-mail, chats and lists of discussion. Based on the analysis of Brazilian academic research in the business area, it was observed that the use of focus group is still incipient, especially in its on-line form. Thus, the present paper aims to characterize OFGs and how it can be conducted, as well as to describe the advantages and disadvantages that result from its aplication, and suggesting its use in qualitative research in administration.

Keywords: focus groups; qualitative research; technology of information

\footnotetext{
1 Mestre e Doutoranda em Administração - Escola de Administração da Universidade Federal do Rio Grande do Sul - Programa de Pós-Graduação em Administração (PPGA/UFRGS).Endereço: Rua Washington Luis, 855 - Centro - Porto Alegre - Rio Grande do Sul - Brasil - CEP 90010-460- E-mail: christine@ea.ufrgs.br

2 Doutor em Administração pela Universidade de São Paulo. Professor-Adjunto da Escola de Administração da Universidade Federal do Rio Grande do Sul Programa de Pós-Graduação em Administração (PPGA/UFRGS). Endereço: Rua Washington Luis, 855 - Centro - Porto Alegre - Rio Grande do Sul - Brasil CEP 90010-460. E-mail:Irklering@via-rs.net
}

Artigo submetido em setembro e aceito em novembro de 2008 


\section{Introdução}

O grupo focal ou focus group, basicamente, consiste numa técnica de pesquisa qualitativa baseada numa entrevista em profundidade realizada em grupos contendo, normalmente, de seis a 10 pessoas, tendo por objetivo captar o entendimento dos participantes sobre o tópico de interesse da pesquisa. Estes influenciam uns aos outros pelas respostas às idéias e pelas colocações feitas durante a discussão, estimulados por comentários ou questões levantados por um moderador. Os dados das discussões do grupo são transcritos e acrescidos das anotações e reflexões do moderador e de outros observadores.

Em face das potencialidades advindas da utilização de computadores e da Internet, uma alternativa à realização da entrevista presencial é a organização de on-line focus groups (OFGs) - também denominados e-focus groups (electronic focus groups) -, o que permite conduzir entrevistas virtuais com o auxílio de ferramentas como e-mail, chats e listas de discussão, substituindo total ou parcialmente as interações presenciais.

Diante dessa perspectiva, a principal motivação deste artigo é inspirar a utilização de on-line focus groups na pesquisa em administração, especialmente em pesquisas de cunho qualitativo. Sobretudo a partir da análise dos trabalhos apresentados nas últimas edições do EnANPAD (Encontro Nacional dos Programas de PósGraduação em Administração), tido como um evento de referência na área, pode-se considerar que a utilização de focus groups na pesquisa em administração ainda seja incipiente, havendo poucas pesquisas que se utilizam dessa técnica. Então, ao se falar em on-line focus groups, poder-se-ia afirmar que, em administração, praticamente não há estudos que os considerem em seu desenho de pesquisa. Também na literatura nacional referente a metodologias de pesquisa em ciências sociais e administração, a técnica na modalidade on-line parece não receber o devido destaque, sobressaindo-se o enfoque nos focus groups tradicionais ou, até mesmo, dando-se à técnica tradicional, meramente, uma visão conceitual e bastante objetiva, sem sequer se mencionar a possibilidade de sua aplicação na modalidade on-line.

Mesmo a literatura internacional especializada não aborda, de forma unânime, a utilização de on-line focus groups, permanecendo a ênfase nos focus groups presenciais, sendo ainda poucos os livros ou artigos de periódicos - especialmente os disponibilizados em meio digital - dedicados à caracterização e à descrição da técnica em sua aplicação on-line.

A despeito do pouco destaque que, percebe-se, tal técnica ainda recebe, a utilização de on-line focus groups (OFGs) pode tornar-se uma alternativa bastante interessante para diferentes pesquisas, inclusive pesquisas em administração, a cuja análise refere-se essencialmente este artigo. Pode ser útil não apenas à pesquisa em marketing, "berço" da utilização da técnica em sua forma presencial, mas a pesquisas em outras áreas. Neste contexto, este ensaio teórico objetiva caracterizar os on-line focus groups, descrevendo as formas de condução da técnica, elencando as principais vantagens e desvantagens decorrentes de sua aplicação e, finalmente, sugerindo algumas possibilidades para o uso de on-line focus groups nas pesquisas em administração.

\section{Caracterizando o focus group e o on-line focus group}

Oliveira e Freitas (1998) definem focus group como um tipo de entrevista em profundidade realizada em grupo, cujas reuniões apresentam características definidas quanto a proposta, tamanho, composição e procedimentos de condução. $\mathrm{O}$ foco ou o objeto de análise é a interação dentro do grupo. Os participantes influenciam uns aos outros pelas respostas às idéias e colocações durante a discussão, estimulados por comentários ou questões fornecidos pelo moderador (pesquisador ou outra pessoa). Os dados fundamentais produzidos por essa técnica são transcritos das discussões do grupo, acrescidos das anotações e das reflexões do moderador e de outro(s) observador(es), caso exista(m).

Como características gerais do focus group, tem-se o envolvimento das pessoas, as reuniões em série, a homogeneidade dos participantes quanto aos aspectos de interesse da pesquisa, a geração de dados, a natureza qualitativa e a discussão focada em um tópico determinado pelo propósito da pesquisa (OLIVEIRA; FREITAS, 1998; KRUEGER, 1994). 
Conforme os mesmos autores, o objetivo do focus group é o entendimento dos participantes sobre o tópico de interesse da pesquisa, não importando se a técnica é utilizada isoladamente ou em conjunto com outros métodos.

Segundo Patton (2002), o processo de entrevistas em focus groups foi desenvolvido em razão de que muitas decisões de consumidores fazem-se, freqüentemente, num contexto social, em decorrência de discussões com outras pessoas. Destarte, os pesquisadores de marketing começaram a utilizar os focus groups nos anos 1950, como forma de, estimulando o processo decisório de um grupo de consumidores, colher informações mais precisas acerca das preferências desses consumidores. Já, no campo acadêmico, Robert K. Merton e pesquisadores a ele associados escreveram, em 1956, o primeiro trabalho sobre pesquisa orientada por entrevistas em focus groups: The focused interview (MERTON; RISKE; KENDALL, 1956).

Oliveira e Freitas (1998) sugerem a utilização do focus group, num sentido geral, para orientar e dar referencial à investigação ou à ação em novos campos, gerar hipóteses baseadas na percepção dos informantes, avaliar diferentes situações de pesquisa ou populações de estudo, desenvolver planos de entrevistas e questionários, fornecer interpretações dos resultados dos participantes a partir de estudos iniciais e, também, para gerar informações adicionais a um estudo em larga escala.

No entanto, há algumas situações nas quais o uso de focus group como método de pesquisa não é recomendável. Por exemplo, quando o assunto é constrangedor para os participantes (embora esse mesmo constrangimento possa ser atenuado pela utilização de $O F G s$, conforme será tratado a seguir), quando o pesquisador não tem controle sobre quais são os aspectos críticos do estudo, quando são necessárias projeções estatísticas, quando outro método pode produzir resultados com melhor qualidade ou maior economia ou, ainda, quando o pesquisador não pode garantir a confidencialidade da informação.

Segundo Morgan (1988), o uso do focus group é particularmente apropriado quando o objetivo é explicar como as pessoas consideram uma experiência, uma idéia ou um evento, uma vez que a discussão durante as reuniões é efetiva em fornecer informações sobre o que as pessoas pensam ou sentem ou, mesmo, sobre a forma como agem com relação ao assunto.

Nesse sentido, Oliveira e Freitas (1998), numa revisão do que trazem Krueger (1994) e Morgan (1988), apontam as seguintes vantagens decorrentes da utilização de focus groups:

- facilidade de condução, comparativamente a outros métodos;

- possibilidade de se explorar tópicos e gerar hipóteses;

- possibilidade de se coletar dados em um curto espaço de tempo e em quantidade adequada;

- oportunidade de coletar dados a partir da interação do grupo, o qual se concentra no tópico de interesse do pesquisador;

- alta validade dos dados, ou seja, além de o procedimento medir efetivamente o que se deseja, tem-se plena legitimidade e convicção (ou crença) nos dados coletados;

- menor custo em relação a outros métodos;

- rapidez no fornecimento dos resultados, em termos de evidência da reunião do grupo; e

- a possibilidade de o pesquisador aumentar a quantidade de sujeitos nos estudos qualitativos.

Como desvantagens ou limitações do emprego de focus groups, podem ser apontadas as seguintes (KRUEGER, 1994; MORGAN, 1988; OLIVEIRA; FREITAS, 1998):

- o fato de a pesquisa não ser baseada em um ambiente natural;

- menor controle do pesquisador sobre os dados gerados (no caso de existir um grupo de questões predefinidas ou uma forte necessidade de se manter comparação entre as entrevistas); 
- a impossibilidade de saber se a interação em grupo, precisamente, reflete ou não o comportamento individual;

- maior dificuldade em se analisar os dados, uma vez que a interação do grupo forma um ambiente social e os comentários devem ser interpretados dentro desse contexto;

- a necessidade de se ter entrevistadores treinados cuidadosamente;

- a dificuldade de reunir as pessoas em grupos; e

- a necessidade de se conduzir a discussão em um ambiente que propicie o diálogo.

Interações baseadas em computador, via Internet, têm possibilitado o surgimento de novas formas de focus groups. Uma vez entendido o ciberespaço como um lugar onde a vida social e a interação alcançam novos significados e padrões (KIM, 2000) - ou uma estrutura infoeletrônica transacional de comunicação de dupla via em tempo real, multimídia ou não (TRIVINHO, 2000) -, as comunidades virtuais podem ser caracterizadas como grupos de pessoas que se comunicam umas com as outras por meios eletrônicos (BELLINI; VARGAS, 2002; ROMM; PLISKIN; CLARKE, 1997; WILLIAMS, 2000). São igualmente chamadas de comunidades online, em que as pessoas com interesses comuns podem interagir através de redes de computadores, na forma "muitos para muitos" (WILLIAMS; COTHREL, 2000).

As comunidades virtuais utilizam diferentes ferramentas de interação - tais como fóruns de discussão, páginas HTML, chats e mensagens instantâneas de texto, áudio e voz, e-mails, áudio e videoconferências - via computadores pessoais, notebooks, palmtops, celulares e televisão digital (TEIXEIRA FILHO, 2002). O objetivo deste artigo não é explorar minuciosamente a utilidade e as características dessas ferramentas, nem os sentidos da existência das comunidades virtuais, mas apenas mencionar tais ferramentas como os meios pelos quais as pessoas interagem nessas comunidades e que podem ser utilizados para possibilitar a interação dos indivíduos, também, em on-line focus groups.

\section{Planejando, conduzindo e analisando on-line focus groups}

Adiante, a partir da revisão da literatura pertinente, são apresentadas as etapas de planejamento, condução e análise de resultados de on-line focus groups.

\section{Planejamento para a realização de on-line focus groups}

Conforme Krueger (1994), Morgan (1988) e Oliveira e Freitas (1998), o planejamento da realização de focus groups inclui etapas como:

- elaboração de orçamento;

- desenvolvimento do plano cronológico;

- desenho dos objetivos e motivações para a realização do estudo, bem como do tipo de informações que se deseja obter, além de como e por quem essas informações serão utilizadas;

- definição da forma de seleção dos participantes;

- definição do local para as discussões (no caso de on-line focus groups, a escolha da plataforma virtual, dos softwares e dos recursos e ferramentas a serem utilizados, como suporte a páginas HTML, fóruns, chats e lista de discussão); e

- escolha do moderador.

No plano cronológico estão inclusas as atividades de desenvolvimento das questões, a identificação das características dos participantes, a obtenção da lista dos potenciais participantes (através de diversas fontes), o recrutamento dos participantes, a condução das reuniões, o feedback do planejamento, a transcrição, a análise e a redação do relatório. Nesse sentido, o planejamento e o desenvolvimento de atividades necessárias à condução de on-line focus groups guarda semelhanças com o mesmo processo realizado nos grupos presenciais 
(SWEET, 1999). Entretanto, persistem diferenças cruciais na condução dos processos entre as duas modalidades, em função do impacto da tecnologia empregada, a qual requer habilidade específica de utilização, além das normalmente requeridas à condução de grupos presenciais.

\section{Condução de on-line focus groups}

Numa revisão de Greenbaum (1993), Krueger (1994), Morgan (1988), Oliveira e Freitas (1998), Oringderff (2004), Patton (2002), Rezabek (2000), Silverman (2006) e Sweet (1999), apresenta-se, a seguir, os elementos principais da condução de on-line focus groups: seleção dos participantes, tamanho dos grupos, conteúdo das entrevistas, condução das entrevistas, indicadores de participação, atribuições do moderador e visão dos respondentes.

\section{a) seleção dos participantes}

Neste processo, o papel do moderador, bem como dos observadores, é fundamental. On-line focus groups podem ser iniciados contactando-se um moderador qualificado ou, então, uma empresa especializada na técnica. Os respondentes podem ser recrutados eletronicamente, a partir de listas virtuais, de listas de stakeholders de quaisquer organizações (clientes, colaboradores, etc.), ou, eventualmente, por telefone, até mesmo para confirmação de dados de contato on-line, como o e-mail. Conforme os propósitos da pesquisa especialmente na pesquisa acadêmica -, os participantes podem ser recrutados diretamente no contexto ou organização em que se dará a pesquisa.

Pode-se fazer uma sessão-piloto do focus group ou, ainda, elaborar-se um questionário inicial, destinado a recrutar os participantes, contendo breves questões de caráter eliminatório (de quatro a seis questões), que permitam identificar se essas pessoas possuem ou não as características indispensáveis para participar das sessões. Nesse aspecto, é importante decidir se os participantes devem ou não saber da identidade do outro, problema particularmente minimizado pelos focus groups on-line, no que concerne à preservação do anonimato.

Os respondentes também devem ser suficientemente qualificados para lidarem com os recursos da informática de forma ágil e adequada.

b) tamanho dos grupos

A quantidade de pessoas no grupo pode variar conforme os objetivos da pesquisa, do tempo destinado às sessões e da quantidade de moderadores. No entanto, a literatura sugere, tanto para os grupos presenciais quanto para os on-line, que os grupos sejam constituídos por seis a 10 pessoas, e que em limites extremos se tenha entre quatro e 12 participantes.

Respondentes e observadores convidados para o grupo passam a ser cadastrados, recebendo nome de usuário e senha (dados de login), além de instruções gerais e informações sobre prazos, datas e horários (nesse último caso, especificamente, quando se opta pela comunicação síncrona). O objetivo é garantir que todos estejam aptos a participar virtualmente da pesquisa. Em caso de dificuldades, os respondentes podem contactar o suporte técnico do site que mantém a pesquisa e também o moderador ou os observadores, para conseguirem suporte on-line.

\section{c) conteúdo das entrevistas}

Merton, Riske e Kendall (1956), mencionados por Morgan (1988), apontam quatro aspectos a serem considerados na entrevista nos focus groups: abordar o máximo de tópicos relevantes; fornecer dados tão específicos quanto for possível; promover interação que explore os sentimentos dos participantes em alguma profundidade; e levar em conta o contexto pessoal tomado pelos participantes na geração de suas respostas. Todavia, tópicos envolvendo questões estritamente pessoais não são recomendados, bem como questões dirigidas a participantes específicos. 
Os tópicos ou questões devem ser previamente elaborados. Um bom roteiro cria uma progressão natural entre os tópicos, com alguma sobreposição entre os mesmos, evitando, assim, uma divisão artificial, e elencando as questões numa sequiência lógica. No entanto, o moderador deve tomar o cuidado de evitar uma excessiva rigidez na condução do roteiro.

O conteúdo e a estrutura das entrevistas assemelham-se ao processo verificado nos grupos presenciais. A maior diferença, no entanto, é que as questões, na forma escrita, são apresentadas mais detalhadamente. Nesse sentido, requer-se que os tópicos centrais que envolvem as questões sejam abordados de forma clara e abrangente, para que os respondentes não percam tempo buscando esclarecimentos.

\section{d) condução das entrevistas}

Os OFGs podem ser conduzidos síncrona ou assincronamente. As sessões síncronas assemelham-se às sessões em focus groups presenciais, pois também ocorrem "ao vivo", em tempo real, com os participantes interagindo simultaneamente em salas virtuais de chat ou conferências, valendo-se de ferramentas de conversação como, por exemplo, ICq, MSN Messenger e Yahoo!Messenger. Quanto às sessões assíncronas, estas geralmente ocorrem através do uso de ferramentas que permitem que a interação não ocorra exatamente em tempo real, como, por exemplo, fóruns virtuais, e-mails ou listas de discussão de e-mails, em que os participantes podem ler as anotações uns dos outros e interagirem, não necessariamente no mesmo instante.

Em média, os on-line focus groups em sessões síncronas duram cerca de 90 minutos, duração esta que pode ser menor ou maior. Todavia, entre os estudos consultados não há consenso com relação à quantidade de questões, tampouco quanto ao número de sessões. Esses fatores variam bastante, dependendo da natureza das questões propostas, da natureza do estudo e, mesmo, do grau de familiaridade dos participantes com o processo on-line, o que faz com que o tempo médio de resposta do grupo possa oscilar. Assim, é recomendável iniciar com poucas questões, podendo-se alterar a quantidade destas ao longo da experiência. No entanto, 90 minutos costumam ser suficientes para que, espontaneamente, sejam inseridas questões adicionais ao diálogo. Algumas experiências atestam, por exemplo, que num grupo de oito pessoas, durante uma hora, não se deve formular mais de 10 questões importantes.

Sugere-se uma seqüência em que sejam lançadas, num primeiro momento, questões abertas que permitam resposta rápida, no sentido de serem identificadas características comuns aos participantes. Num segundo momento, viriam as questões introdutórias, de apresentação do tópico geral. Num terceiro momento, seriam lançadas questões de transição, as quais conduzem a conversação para questões-chave norteadoras do estudo. Posteriormente, viriam questões-chave, que requerem maior atenção e análise, e questões finais, direcionando para a finalização da discussão e considerando tudo o que fora dito anteriormente. Após, viriam questõesresumo, em que o moderador apresenta uma síntese das questões-chave e grandes idéias surgidas da discussão, indagando-se ao grupo quanto à adequação daquela síntese. Finalmente seria, então, lançada uma questão final, formulada imediatamente após a questão-resumo, quando o moderador faria uma breve explanação acerca do propósito do estudo, solicitando sugestões ao grupo.

Além disso, a primeira sessão pode ser utilizada como teste-piloto do on-line focus group, tanto no sentido de reelaborar as questões e replanejar sua quantidade com relação à duração das sessões, quanto no sentido de, por exemplo, apurar a necessidade de se ter mais de um moderador (moderador assistente) ou de se descartar participantes, conforme já comentado. Nessas sessões, convém considerar, à parte, 30 minutos antes que a entrevista em grupo efetivamente comece, prevenindo possíveis contratempos, bem como se sugere, ainda, que o moderador deixe sempre explícitas as limitações de tempo do processo.

Nas sessões assíncronas, através de fóruns, por exemplo, tende-se a considerar um prazo de três a cinco dias ou mais, para que se possa colher informações suficientes. No início de cada dia, há um dado número de questões que pode ser postado para instigar os participantes a responder. O número de questões diárias, entretanto, depende da complexidade dos temas relacionados aos tópicos, bem como do tempo disponível e do nível de envolvimento dos respondentes. Durante o processo de respostas ao longo do dia, questões adicionais podem 
ser colocadas para reelaboração dos tópicos ou, mesmo, para a adição de novos assuntos. Todavia, a interação unicamente via e-mail, nos grupos assíncronos, pode ainda ser mais lenta, menos dinâmica e menos sofisticada.

Com relação ao encerramento das entrevistas, pode-se optar tanto pela palavra final do moderador quanto pela solicitação, por parte deste, de que cada participante faça seu fechamento.

\section{e) indicadores de participação}

Os indicadores de participação podem variar significativamente em função de fatores como as diferentes motivações dos participantes, a origem dos respondentes, as formas pelas quais sua participação foi confirmada, o grau de familiaridade com as ferramentas virtuais e as atribuições pessoais e profissionais que podem inibir a atenção dispensada à entrevista, bem como outros contratempos (por exemplo, problemas que ocasionem falta de acesso a computadores, intempéries, problemas de deslocamento, etc.).

Outro aspecto a ser considerado é a possibilidade de desistência ou mesmo de falta de aptidão dos participantes. Tanto para os grupos on-line assíncronos quanto para os síncronos, o número de respondentes selecionados é, geralmente, de 50 a 100\% maior do que o desejado, sendo sua seleção final confirmada pelo moderador e pelos observadores. Além do mais, esse percentual é variável, uma vez que a literatura chega a apontar, para os grupos presenciais, um mínimo de $20 \%$ de pessoas a mais a serem convocadas para que haja garantia do número mínimo desejado. Dadas as peculiaridades da aplicação de grupos on-line, o percentual de respondentes que podem desistir ou mesmo serem considerados inaptos tende a ser tão ou mais significativo que nas entrevistas presenciais.

\section{f) atribuições do moderador}

Ao iniciar um grupo, o moderador faz sua apresentação pessoal, identificando-se como líder e condutor do grupo. Apresenta os objetivos do grupo e as normas de condução do processo (por exemplo, declarando que somente uma pessoa se expressará por vez, que não deve haver conversas paralelas, que todos devem se manifestar, etc.). Além disso, determina a duração da entrevista, dá instruções para a postagem das respostas e incentiva os participantes a colocarem abertamente o que pensam (concordando ou discordando), estimulandoos, ainda, a questionarem uns aos outros, dentro da temática proposta. Também pode conduzir a apresentação pessoal entre os membros do grupo.

Destarte, os grupos on-line demandam um moderador ágil, incisivo e atencioso - preferencialmente, experiente na condução de grupos on-line -, que possa dedicar tempo considerável (e não eventual) à monitoração. $\mathrm{O}$ moderador deve ter habilidade para responder a interações simultâneas dos participantes, mas para tanto deve ter familiaridade com o sistema e ser ágil na digitação e elaboração de seus comentários.

É essencial que o moderador considere que os participantes não têm de, necessariamente, ter conhecimento prévio sobre o funcionamento do grupo, dispondo-se a fazer com que os menos experientes se sintam mais à vontade e valorizados. Também precisa, junto aos observadores (ou mesmo a um segundo moderador), caso existam, apresentar a todos os principais aspectos técnicos relativos ao funcionamento do grupo. $\mathrm{O}$ moderador deve ainda, antes de o grupo iniciar suas atividades, testar todas as funcionalidades do sistema, cabendo também a ele certificar-se de que todos os browsers (softwares de acesso à Internet, como, por exemplo, o Microsoft Internet Explorer e o Mozilla Firefox) sejam compatíveis com os recursos da plataforma utilizada.

Compete ao moderador planejar um roteiro de discussão completo e conciso, e mesmo reelaborar questões quando for verificado que estas podem levantar dúvidas de interpretação por parte dos respondentes. Ele também deve estar apto para buscar e selecionar, on-line, os participantes mais adequados para contribuir com a discussão, bem como manter juntos aqueles com desenvoltura na utilização dos meios eletrônicos. Da mesma forma, são responsabilidades do moderador assegurar o respeito a algumas normas de etiqueta on-line netiquette (por exemplo, evitando que os participantes digitem em maiúsculas, o que poderia evidenciar agressividade) e manter o foco da discussão, pois o focus group on-line tende a não tratar tão formalmente o processo, o que permite o surgimento de tópicos não relacionados. 
Ao moderador também cabem tarefas como acompanhar "murais" ou outras ferramentas de comunicação do sistema (ambiente virtual) utilizado, paralelamente ao processo da entrevista em si, bem como orientar previamente aos participantes sobre a utilização dessas ferramentas. Pode o moderador, então, instruir aos respondentes para que esperem o retorno de todos antes de fazerem seus comentários e, assim, ele possa retomar a discussão. Além disso, deve buscar agendar as sessões conforme os fusos horários ou as possibilidades de participação dos respondentes (no caso de sessões síncronas). Deve, ainda, explicar aos participantes sobre como procederem em casos de possível queda de conexão (especialmente se a sessão for síncrona). Na introdução do grupo e, posteriormente, em cada sessão, o moderador deve considerar, pelo menos, cerca de 20 a 30 minutos à parte para lidar com quedas de conexão, observar o "movimento" na sala virtual e confirmar o funcionamento do software.

No caso de várias questões serem abordadas quase simultaneamente, convém que o moderador atribua um número a cada questão-chave da discussão e instrua os respondentes a numerarem, nesse sentido, suas respostas. Ademais, o moderador pode postar as questões em "caixa alta" (POR EXEMPLO) para facilitar o reconhecimento de seus comentários pelos demais, especialmente em uma extensa lista de discussão, valendose, se for o caso, de cores ou estilos diferentes, caso a ferramenta empregada permita.

Em suma, alguns dos cuidados a serem tomados pelos moderadores seriam:

- saber estabelecer comunicação em harmonia;

- evitar o excesso de formalismo ou de artificialidade;

- evitar dar muita atenção à estrutura;

- saber ouvir;

- evitar o uso de jargões (terminologia técnica);

- evitar pedir às pessoas que expliquem (justifiquem) seu comportamento;

- não formular, inapropriadamente, questões vagas, nem questões específicas que possam induzir as respostas dos participantes;

- saber interagir com os participantes de forma objetiva, mais do que agir como "advogado do diabo";

- evitar fazer referências elogiosas a comentários específicos dos participantes;

- estar atento aos momentos em que os participantes se mantiverem em silêncio;

- preocupar-se em tornar a entrevista interessante, mantendo a motivação e o interesse do grupo;

- não permitir que uma única pessoa fale em nome do grupo ou que uma ou duas pessoas dominem a discussão;

- evitar tirar conclusões precipitadas a partir das diversas opiniões dos participantes;

- ser ativo sem que, no entanto, sua participação torne a discussão "enviesada".

g) visão dos respondentes

Os respondentes têm acesso a todas as questões lançadas pelo moderador, bem como aos comentários uns dos outros. Cada respondente é identificado por um nome de usuário (freqüentemente um pseudônimo). Um recurso visual interessante é a sinalização, em cores diferentes, das respostas de cada um, a exemplo do que pode fazer o moderador, conforme já mencionado. No entanto, o sistema empregado pode permitir, se for o caso, que os participantes não visualizem as notas dos observadores ou as notas de observação do moderador.

Análise e geração de relatórios de resultados dos on-line focus groups

O processo de geração e análise de resultados ocorre de forma semelhante ao dos grupos presenciais, com exceção da etapa de transcrição, que é automática e disponibilizada imediatamente para todo o grupo. Na 
ausência de expressões visuais e vocais, a análise é baseada apenas na interpretação das sentenças dos respondentes. Nesse sentido, são duas as formas básicas de análise dos dados do focus group: qualitativa (ou resumo etnográfico) e sistemática codificação através da análise de conteúdo. Na abordagem etnográfica são relevantes as citações diretas da discussão do grupo, enquanto na análise de conteúdo é valorizada a descrição mais em termos de quantidade dos dados. Salienta-se que essas duas formas de análise não são conflitantes, mas complementares, tendendo-se a dar maior ênfase à análise de conteúdo. Uma vez que o uso de focus group refere-se, essencialmente, a resultados não generalizáveis, o pesquisador deve ter o cuidado de não tomar os dados obtidos a partir dos sujeitos pesquisados como representativos do universo (OLIVEIRA; FREITAS, 1998).

As análises podem vir a ser disponibilizadas ao grupo através de relatórios contendo objetivos, metodologia e conclusões da pesquisa, como no uso de outras técnicas qualitativas, tanto de forma sumária quanto em relatórios completos. Tipicamente, o processo de geração de relatórios é bastante agilizado, nesses grupos, pelo fato de se ter imediato acesso às transcrições (SWEET, 1999). O relatório é composto, normalmente, por um conjunto de citações, de resumos das discussões e de tabelas e mapas ou de esquemas contendo informações básicas relacionadas a cada tópico da discussão. Finalmente, um ponto importante a ser decidido é se a análise de conteúdo poderá ser feita diretamente pelo pesquisador ou se será realizada com apoio de softwares específicos.

\section{Possibilidades de utilização de on-line focus group em combinação com outros métodos}

Como um método com conteúdo próprio, o focus group pode ser usado para explorar novas áreas de pesquisa e examinar questões de pesquisa bem conhecidas a partir da perspectiva dos participantes. Em conjunto com outras técnicas, o focus group também pode ser usado como uma pesquisa preliminar para preparar questões específicas em um grande projeto ou como uma pesquisa para esclarecer resultados de outros estudos. Nesse sentido, o posicionamento do focus group no desenho da pesquisa é definido pelo objetivo de sua aplicação.

Como afirmam Oliveira e Freitas (1998), os pesquisadores vêm reconhecendo as vantagens de se associar métodos qualitativos e quantitativos, utilizando-se de combinações metodológicas que fortalecem os desenhos de pesquisa. Nesse contexto, o focus group pode vir a (GREENBAUM, 1993; KRUEGER, 1994; MORGAN, 1988; OLIVEIRA; FREITAS, 1998; SWEET, 1999):

- preceder um método quantitativo, não somente auxiliando o pesquisador a assimilar o vocabulário e a descobrir (ou identificar mais claramente) o pensamento do público-alvo, mas também fornecendo indícios de dificuldades que podem vir a ocorrer na fase quantitativa;

- ser utilizado simultaneamente com procedimentos quantitativos, tendo-se, então, uma triangulação de métodos para um mesmo problema de pesquisa; ou

- suceder um método quantitativo, esclarecendo questões que tenham surgido quando da análise dos resultados da fase quantitativa.

Eis, a seguir, alguns exemplos da associação do focus group com outras técnicas de pesquisa.

\section{Focus group e entrevista individual}

O focus group pode ser útil no planejamento do roteiro das entrevistas individuais, através da utilização de pequeno número de grupos exploratórios em estágio inicial da pesquisa para, a posteriori, orientar-se a construção das questões da entrevista. Uma rodada preliminar com focus group também pode fornecer a base para a seleção dos grupos para entrevistas mais detalhadas. Outra forma de associar o focus group com a entrevista individual é conduzir os grupos como um recurso "adicional" para as entrevistas individuais, permitindo ao pesquisador explorar questões surgidas na análise dessas entrevistas, com a finalidade de esclarecer elementos que ainda apresentem pontos obscuros. 


\section{Focus group e observação participante}

O focus group permite, em um curto espaço de tempo, identificar a percepção do pensamento concentrado dos membros do grupo sobre o tópico objeto da investigação. Se a técnica for aplicada anteriormente à observação participante, poderá auxiliar na decisão entre situações alternativas para a realização dessa observação; sucedendo à observação, seu objetivo será auxiliar na comparação entre as observações já registradas.

\section{Focus group e survey}

Recomenda-se o uso de focus groups para subsidiar a elaboração de questionários, pois a técnica pode oferecer evidências de como será o posicionamento dos respondentes quanto ao tópico que está sendo discutido. O uso dos focus groups é bastante interessante como técnica preliminar a uma survey, quando se busca garantir que o pesquisador tenha um quadro completo do pensamento dos participantes, embora também possa se dar numa ampliação da etapa pré-teste, montando-se um grupo para discussão dos itens cruciais do questionário, antes do pré-teste em campo. O pré-teste com focus groups não apenas permite identificar problemas, mas também explorar, imediatamente, formas de resolvê-los. Outra aplicação do focus group consiste na sua utilização como forma adicional de coleta de dados, buscando explorar aspectos da análise.

\section{Focus group e experimentos}

O focus group pode ser utilizado, preliminarmente, para definir manipulações da variável independente e medir as variáveis dependentes, quando associado a um experimento. Também pode ser útil para substituir efetivamente a especulação, na tentativa de explicar resultados anormais. Outra vantagem de combinar o focus group com os experimentos está na possibilidade de se ampliar a interpretação de como realmente operam os efeitos induzidos de maneira experimental. Como ocorre na combinação com outros métodos, o objetivo é comparar as interpretações do pesquisador e dos participantes sobre determinado evento.

\section{Vantagens e desvantagens da utilização de on-line focus groups}

A seguir, são elencadas algumas vantagens e desvantagens decorrentes da utilização de $O F G s$, identificadas a partir dos estudos de Alvarez et al (2005), Chase e Alvarez (2000), Clapper e Massey (1996), Edmunds (1999), Krueger e Casey (2000), Munro e Zeidman-Karpinski (2003), O'Connor e Madge (2003), ODCIO (2006), Oringderff (2004), Patton (2002), Silverman (2006), Smith, Cadiz e Burkhalter (2000), Sweet (1999) e de Walston e Lissitz (2000).

\section{Vantagens decorrentes da utilização de OFGs}

Pode-se considerar como vantagens decorrentes do emprego de $O F G s$ o fato de que:

- estes possibilitam que se disponibilize acesso restrito, ou seja, apenas a participantes previamente autorizados;

- participantes considerados inaptos ou desrespeitosos podem ser virtualmente bloqueados ou, mesmo, aconselhados a abandonar a pesquisa;

- a transcrição das entrevistas é gerada automaticamente, palavra por palavra;

- os OFGs permitem que outros formulários de levantamento sejam preenchidos on-line, durante a própria sessão do focus group;

- os $O F G s$ permitem a utilização de elaborados controles de moderação (mediação) eletrônica;

- os grupos on-line garantem a disponibilidade (sem que se exija a interferência dos participantes) de materiais de base para a discussão - como slides, quadros, painéis, artigos e outros materiais textuais -, possibilitando dar continuidade a uma discussão numa tela à parte, enquanto, simultaneamente, pode-se visualizar os diferentes materiais disponibilizados; 
- a interação mediada por computador, aparentemente, reduz a ansiedade dos membros com relação ao que o moderador pensa a respeito destes, permitindo, assim, que sejam compartilhadas informações antes vistas como embaraçosas;

- esse tipo de interação tem potencial para uma maior abrangência geográfica;

- os grupos on-line podem ser constituídos ou desfeitos rapidamente;

- os grupos on-line podem ser baseados em software de relativa simplicidade, cuja licença seja livre ou de baixo custo;

- a questão do anonimato torna o processo mais efetivo. As pessoas que acreditam que, em questão de opinião, representam minoria, não precisam temer reações negativas e podem expressar suas opiniões com tranqüilidade, uma vez que não se sentem intimidadas pelas expressões, pelo tom de voz, pelos trajes e olhares das outras pessoas, ao contrário do que normalmente ocorre em grupos presenciais. Além do mais, a confidencialidade não pode ser assegurada pelos focus groups tradicionais, mesmo porque, por exemplo, em pesquisas de marketing, as sessões dos focus groups presenciais geralmente são gravadas, permitindo que os pesquisadores analisem as reações emocionais dos entrevistados;

- a distância e os custos de viagem são eliminados tanto para participantes quanto para os moderadores/administradores. Qualquer um no mundo, com um computador, Web browser e acesso à Internet pode participar. On-line focus groups podem facilmente recrutar participantes de regiões distantes, até mesmo transpondo os limites nacionais;

- digitar em um teclado pode ser mais lento do que falar. Entretanto, comentários (anotações) são freqüentemente mais ponderados, focados e proveitosos quando os participantes são compelidos a escrevê-los, sobretudo quando a comunicação for assíncrona, ressaltando-se o fato de que a transcrição é feita automaticamente, conforme já comentado;

- moderadores de on-line focus group não necessitam ter a capacidade de perceber expressões faciais, linguagem do corpo, conversas laterais e outros movimentos do grupo;

- é permitido o acesso de pessoas ou profissionais que dispõem de pouco tempo livre para participar de uma pesquisa, sendo possível a participação dessas pessoas mesmo durante seu horário de expediente. As possibilidades de participação crescem, especialmente, na comunicação assíncrona;

- os OFGs possibilitam ao entrevistado responder às questões, por exemplo, em casa ou no escritório, o que é mais prático e confortável;

- os on-line focus groups podem ser mais atrativos para os participantes que se sintam intimidados em manifestar pessoalmente sua opinião acerca de determinados assuntos, como, por exemplo, política, religião e convenções sociais;

- o desenvolvimento de focus groups on-line propicia aparente equalização social (de classe social, raça, nacionalidade e gênero), uma vez que tais características não necessariamente precisam ser identificadas entre os participantes, permitindo, assim, uma coleta de dados "homogênea"; e

- as reações e opiniões iniciais dos participantes tendem a ser mais espontâneas em tempo real com a comunicação síncrona, o que pode dar aos pesquisadores resultados mais confiáveis.

\section{Desvantagens decorrentes da utilização de OFGs}

As desvantagens associadas ao uso de $O F G s$ seriam, essencialmente, as seguintes:

- os participantes dos OFGs devem, obviamente, ter acesso a computadores e a um nível básico de "alfabetização digital" (familiaridade com a tecnologia), da mesma forma que, para se garantir o êxito da condução da entrevista, é necessário que os participantes tenham agilidade no digitar. Quem digita mais devagar envia a resposta bem depois dos demais, quando já estão sendo respondidas outras questões. Uma forma de minimizar o problema é solicitar que os participantes aguardem as respostas 
de todos para se expressarem novamente (nesse sentido, recomenda-se a indicação de pausas entre as questões, o que também é orientado aos grupos presenciais);

- há dificuldades na definição da ordem das colocações, que surgem de acordo com a velocidade em que as frases são digitadas e enviadas. O retorno nem sempre aparece na sequiência;

- os on-line focus groups ainda são particularmente apropriados para tópicos relacionados à tecnologia em si, como simulações on-line, Web sites, publicidade, bases de dados on-line e fontes de informação, entre outros;

- as conferências on-line - especialmente com uso de conexão discada via modem - não são processos cujo sucesso seja garantido, em face da possível ocorrência de problemas como oscilações de energia, tráfego de linhas telefônicas, bem como dificuldades com servidores e computadores, além de outros transtornos eventuais. No entanto, focus groups tradicionais também podem ser afetados por eventos como interrupção de energia, cancelamentos de vôos, intempéries, problemas com equipamentos, etc.;

- a seleção de participantes pode ser dificultada pelo fato de ficar restrita a pessoas que, seguramente, tenham acesso a computadores;

- a escolha de um moderador capacitado é uma condição crucial para o êxito do grupo;

- a falta de expressões não-verbais ou vocais (como postura, gestos corporais e entonação da voz) pode ter um efeito negativo, uma vez que a análise é unidimensional (apenas textual), podendo o significado das ações ser erroneamente interpretado. Todavia, um ambiente on-line, algumas vezes, proporciona aos indivíduos maior liberdade de expressão, o que exige, assim, maior cuidado com a linguagem, especialmente, em tópicos considerados "delicados" e "polêmicos";

- há uma tendência a que os participantes - particularmente em um grupo que perdure por mais tempo - desenvolvam "parcerias" exclusivas para diálogo dentro do grupo, em detrimento dos demais indivíduos;

- uma importante questão a ser considerada refere-se a quanto, realmente, o anonimato está sendo garantido, e em que medida se tem efetiva segurança nos processos de autenticação, que podem ser vulneráveis a ataques de hackers (invasores de sistemas de computação);

- a realização de grupos assíncronos, ainda que possivelmente conferindo maior qualidade ao processo, pode torná-lo mais lento;

- as sessões síncronas apresentam, como desvantagens, certa dificuldade de condução ao se reunirem simultaneamente pessoas em condições de tempo e espaço diferentes (dada a diferença de fusos horários, por exemplo) e o fato de que alguns softwares utilizados para a conversação nas salas virtuais não necessariamente salvam as transcrições, restando ao moderador buscar outra alternativa para o registro das interações, caso isso ocorra;

- a discussão pode perder seu foco mais facilmente do que numa sessão presencial;

- num grupo eletrônico, é difícil interpretar os momentos de silêncio ocorridos nas reuniões;

- alguns sujeitos da pesquisa podem se sentir inseguros por estarem redigindo textos e pelo fato de as informações estarem sendo registradas e avaliadas;

- erros de digitação e gramaticais são comuns, devido à rapidez com que são digitados os textos (recomenda-se, então, empregar frases simples e curtas);

- o processo é significativamente impactado por fatores como a capacidade do computador e a velocidade da rede, que devem ser semelhantes entre os participantes do grupo, uma vez que as colocações precisam ser interpretadas em tempo real, no caso de uma sessão síncrona; e 
- em comparação com outras técnicas de pesquisa qualitativa, os focus groups, geralmente, apresentam a desvantagem de serem aplicados em um espaço fora do contexto natural onde as interações sociais normalmente ocorrem, o que se aplica - também e de forma mais explícita - aos OFGs.

\section{Algumas possíveis aplicações dos on-line focus groups na pesquisa em administração}

Na pesquisa em gestão, sobretudo em marketing, o focus group tende a ser considerado preliminarmente ou como uma ferramenta exploratória, devendo seus resultados serem verificados por meio de um trabalho quantitativo, em uma amostra representativa (OLIVEIRA; FREITAS, 1998). Do ponto de vista da ciência social, ele é utilizável pelo seu próprio conteúdo e como um complemento para métodos tanto qualitativos quanto quantitativos. Atualmente, as duas principais técnicas de coleta de dados qualitativos consideradas pela ciência social são a entrevista individual e a observação participante em grupos. O focus group, como uma entrevista em grupo, combina elementos dessas duas abordagens. Como os focus groups têm sido utilizados mais largamente em atividades de desenvolvimento organizacional e em pesquisas de avaliação, por exemplo, novas possibilidades têm surgido no sentido de adaptar as técnicas de pesquisa a tais propósitos.

Principalmente a partir do que é trazido por Patton (2002) e Sweet (1999), pode-se sugerir algumas possibilidades de utilização de $O F G s$ em pesquisas no campo da administração:

\section{a) marketing}

OFGs podem ser utilizados para a investigação de reações a produtos novos ou existentes.

\section{b) controle de qualidade}

On-line focus groups podem contribuir para que se consiga um feedback mais específico e bastante significativo no âmbito da prestação de serviços e da formulação de programas, um feedback resultante de uma motivação maior do que a obtida com questionários individuais ou surveys.

\section{c) gestão de pessoas}

On-line focus groups podem ser utilizados para a avaliação de programas de treinamento - inclusive de treinamento virtual -, para identificar pontos fortes, pontos fracos e possíveis impactos, podendo existir os focus groups antes, durante ou depois da realização dos programas. Também podem ser utilizados em estudos de cultura organizacional. Além disso, podem ser criadas e mantidas comunidades virtuais através da criação de um on-line focus group em torno de um tópico específico.

\section{d) planejamento}

As discussões nos $O F G s$ podem servir para fomentar a elaboração de planos diretores e setoriais, por exemplo.

\section{e) sistemas de informação}

OFGs podem ser utilizados para pesquisas relacionadas a comércio eletrônico, avaliação e desenvolvimento de websites, bem como pesquisas relacionadas à produção de tecnologia.

\section{f) estudos organizacionais}

OFGs podem ser utilizados não apenas para promover discussões sobre aspectos teóricos e práticos dos estudos organizacionais, mas também para a compreensão das interações em diferentes formas de organização, e não exclusivamente em empresas.

Ainda, o uso de OFGs é recomendado para pesquisas em torno de temas mais "delicados", em relação aos quais as pessoas tendem a ficar mais à vontade se participarem sob anonimato. É o caso, por exemplo, das 
ciências da saúde, no que diz respeito aos estudos relacionados ao HIV-AIDS (KAMBERELIS; DIMITRIADIS, 2005; MACNAGHTEN; MYERS, 2004; SWEET, 1999).

Numa análise de Kamberelis e Dimitriadis (2005), percebe-se que os focus groups também permitem aos pesquisadores explorar a natureza e os efeitos do discurso social por meios que não são possíveis através de entrevistas e de observações individuais. Entrevistas individuais desconsideram a dinâmica crítica e interacional que constitui muito da prática social e da construção coletiva de significados. Contrastando com as meras observações, os focus groups podem ser usados estrategicamente para cultivar novas formas de dinâmicas de interação e, então, possibilitar o acesso a diferentes tipos de informações.

A pesquisa em focus groups consiste, destarte, num campo aberto para a interação entre pedagogia, política e pesquisa interpretativa. Num nível prático, os focus groups são eficientes no sentido de que geram expressivo material a partir de, relativamente, pequeno grupo de pessoas em pouco tempo. Devido ao seu potencial sinérgico, focus groups freqüentemente produzem dados raramente obtidos através de entrevistas e observações individuais. Assim, conseguem-se poderosos insigths interpretativos, à medida que se tende a captar a riqueza $\mathrm{e}$ a profundidade das expressões em grupo, o que pode, inclusive, permitir aos pesquisadores acesso a formas de interação social que produzem memórias particulares, posições, ideologias, práticas e desejos entre grupos específicos de indivíduos.

\section{Considerações finais: desafios e possibilidades}

Este artigo apresentou uma contextualização teórica envolvendo a aplicabilidade dos $O F G s$ à pesquisa qualitativa em administração, caracterizando sua metodologia e suas etapas de realização, identificando-se, a partir da literatura pertinente, as principais vantagens e desvantagens que podem decorrer de seu emprego, sobretudo em comparação com a técnica de utilização de focus groups presenciais.

Como prováveis desafios à criação e condução de $O F G s$ para a pesquisa qualitativa em administração, especialmente, no Brasil, pode-se apontar:

- o fato de que a literatura nacional em métodos de pesquisas pouco considera a possibilidade de se manter focus groups virtualmente;

- a pouca disseminação de informações - em especial, junto à comunidade acadêmica das ciências sociais e humanas - sobre as facilidades proporcionadas pela utilização, em pesquisas, das ferramentas virtuais de interação -, o que também envolve uma importante questão cultural relacionada à própria formação e a possíveis resistências por parte dos pesquisadores e de potenciais participantes da pesquisa;

- a necessidade de se ter certo preparo ou a "alfabetização digital" dos entrevistados, além de suficiente suporte tecnológico (Internet rápida, computadores adequados, disponibilidade de softwares de interatividade a baixo ou mesmo a nenhum custo);

- a necessidade de uma qualificação diferenciada por parte do moderador; e

- o fato de que a literatura em administração, nacional e internacional, quando menciona a criação de OFGs, ainda o faz, predominantemente, voltada para a pesquisa mercadológica (em particular, a nãoacadêmica), tendendo a excluir outras possibilidades de pesquisa qualitativa em áreas como gestão de pessoas e estudos organizacionais, por exemplo.

Numa perspectiva futura, que podemos considerar visivelmente já se aproximando, on-line focus groups podem vir a contar com recursos sofisticados como áudio e vídeo em tempo real, voz sobre IP (Internet Protocol), reconhecimento de voz e videoconferência entre os respondentes individuais (SWEET, 1999). A questão da imagem e da voz pode ser interessante para a percepção da expressão corporal, buscando-se, assim, superar as limitações da comunicação escrita e outras desvantagens já apontadas, pelo fato de que a técnica, tendo as vantagens de ser on-line, também passa a reassumir as peculiaridades da sua aplicação na forma presencial. 
Nesse contexto, todavia, um importante cuidado a se tomar refere-se ao estabelecimento de limites entre a necessidade de anonimato e o excesso de impessoalidade no processo.

Concluindo, esta descrição da dinâmica dos $O F G s$, mesmo detalhada, não pode ser considerada exaustiva. Assim, como principal sugestão de pesquisa a partir deste artigo, propõe-se o acompanhamento da aplicação de OFGs a pesquisas em administração com enfoque qualitativo, através de estudos empíricos, explorando na prática essa possibilidade de pesquisa, acompanhando e analisando em profundidade os $O F G s$, não apenas em termos de resultados obtidos, mas, principalmente, em termos de processo de pesquisa qualitativa. 


\section{Referências}

ALVAREZ, Maria do Carmo Avamilano et al. A técnica do grupo focal em salas de bate-papo na avaliação de bibliotecas virtuais. In: CONGRESSO MUNDIAL DE INFORMAÇÃO EM SAÚDE E BIBLIOTECAS, 9., 2005, Salvador. Anais eletrônicos... Salvador: $\quad$ ICML9/CRICS7, $2005 . \quad$ Disponível em: <www.icml9.org/program/track10/public/documents/Maria\%20do\%20Carmo\%20Avamilano\%20Alvarez-153058.doc>. Acesso em: 9 jul. 2006.

BELLINI, Carlo Gabriel P.; VARGAS, Lilia M. Comunidades mediadas pela Internet: por uma base conceitual. In: ENCONTRO NACIONAL DA ASSOCIAÇÃO NACIONAL DOS PROGRAMAS DE PÓS-GRADUAÇÃO EM ADMINISTRAÇÃO, 26., 2002, Salvador. Anais... Salvador: Enanpad, 2002. v.1, p.1-15.

CHASE, Lynne; ALVAREZ, Jaquelina. Internet research: the role of the focus group. Library and Information Science Research, Perth, Western Australia, v.22, n.4, p.357-369, 2000.

CLAPPER, Danial L.; MASSEY, Anne P. Electronic focus group: a framework for exploration. Information and Management, Amsterdam, v.30, n.1, p.43-50, Jan.1996.

EDMUNDS, Holly. The focus group research handbook. Lincolnwood, IL: NTC Business Books/Contemporary Publishing, 1999.

GREENBAUM, Thomas L. The handbook for focus group research. New York: Lexington Books, 1993.

KAMBERELIS, George; DIMITRIADIS, Greg. Focus groups: strategic articulations of pedagogy, politics, and inquiry. In: DENZIN, Norman K.; LINCOLN, Yvonna S. (Org.). The Sage handbook of qualitative research. $3^{\text {rd }}$ ed. Thousand Oaks, California: Sage Publications, 2005. p.887-907.

KIM, Jong-Young. Social interaction in computer-mediated communication. Bulletin of the American Society for Information Science, v.26, n.3., p.15-17, Feb./Mar.2000.

KRUEGER, Richard A. Focus group interviews: a practical guide for applied research. $2^{\text {nd }}$ ed. Thousand Oaks, California: Sage Publications, 1994.

2000.

; CASEY, Mary Anne. Focus group: a practical guide for applied research. $3^{\text {rd }}$ ed. Thousand Oaks: Sage Publications,

MACNAGHTEN, Phil; MYERS, Greg. Focus groups. In: SEALE, Clive et al (Org.). Qualitative research practice. London: Sage Publications, 2004. p.65-90.

MERTON, Robert K.; RISKE, Marjorie; KENDALL, Patricia L. The focused interview. New York: Free Press, 1956.

MORGAN, David L. Focus groups as qualitative research. Newbury Park, California: Sage Publications, 1988.

MUNRO, Karen; ZEIDMAN-KARPINSKI, Annie. A hitchhiker's guide to chat. OLA Quarterly, Salem, Oregon, v.9, n.2, p.26, summer 2003.

O'CONNOR, Henrietta; MADGE, Clare. Focus group in cyberspace: using the Internet for qualitative research. Qualitative Market Research, Birmingham, United Kingdom, v.6, n.2, p.133-143, Feb. 2003.

ODCIO. Appendix a-7: summary of process for conducting an on-line focus group. 2006. Disponível em: <http://irm.cit.nih.gov/itmra/weptest/app_a7.htm>. Acesso em: 10 jul. 2006.

OLIVEIRA, Mírian; FREITAS, Henrique M. R. de. Focus group - pesquisa qualitativa: resgatando a teoria, instrumentalizando o seu planejamento. Revista de Administração da USP - Rausp, São Paulo, v.33, n.3, p.83-91, jul./set. 1998.

ORINGDERFF, Jennifer. "My way": piloting an on-line focus group. International Journal of Qualitative Methods, Edmonton, Alberta, Canada, v.3, n.3, Sept. $2004 . \quad$ Disponível em: < http://www.ualberta.ca/ iiqm/backissues/3 3/html/oringderff.html>. Acesso em: 13 jul. 2006.

PATTON, Michael Quinn. Qualitative research \& evaluation methods. $3^{\text {rd }}$ ed. Thousand Oaks, California: Sage Publications, 2002. p.385-391.

REZABEK, Roger J. On-line focus groups: electronic discussions for research. Forum: Qualitative Sozialforschung/Forum: Qualitative Social Research (On-line Journal), Berlin, Germany, v.1, n.1. Jan. 2000. Disponível em: <http://www.qualitative-research.net/fqs-texte/1-00/1-00rezabek-e.htm>. Acesso em: 8 jul. 2006. 
ROMM, Celia T.; PLISKIN, Nava; CLARKE, Rodney. Virtual communities and society: toward an integrative three phase model. International Journal of Information Management, Kidlington, v.17, n.4, p.261-270, Aug. 1997.

SILVERMAN, George. Market Navigation Inc. 2006. Disponível em: <http://www.mnav.com/default.htm>. Acesso em: 13 jul. 2006.

SMITH, Mark.; CADIZ, J. J.; BURKHALTER, Byron. Conversation trees and threaded chats. In: PROCEEDINGS OF THE 2000 ACM CONFERENCE ON COMPUTERS SUPPORTED COOPERATIVE WORK, Philadelphia (US). Anais... New York: ACM Press, Dec. 2000. p.97-105.

SWEET, Casey. Designing and conducting virtual focus groups. 1999. Disponível em: <http://www.sysurvey.com/tips/designing and conducting.htm>. Acesso em: 13 jul. 2006.

TEIXEIRA FILHO, Jayme. Comunidades virtuais: como as comunidades de prática na Internet estão mudando os negócios. Rio de Janeiro: Senac, 2002.

TRIVINHO, Eugênio. Epistemologia em ruínas: a implosão da teoria da comunicação na experiência do ciberespaço. In: MARTINS, Francisco Menezes; DA SILVA, Juremir Machado (Org.). Para navegar no século XXI. Porto Alegre: Sulina; Edipucrs, 2000. p.179-192.

WALSTON, Jill T.; LISSITZ, Robert W. Computer-mediated focus groups. Evaluation Review, Los Angeles, CA, v.24, n.5, p.457-483, Oct. 2000.

WILLIAMS, Matthew. Virtually criminal: discourse, deviance and anxiety within virtual communities. International Review of Law, Computers \& Technology, v.14, n.1, p.95-104, Mar. 2000.

WILLIAMS, Ruth L.; COTHREL, Joseph. Four smart ways to run on-line communities. Sloan Management Review, MIT, Cambridge, v.41, n.4, p.81-91, Summer 2000. 